\title{
Erratum to: EANM '15 Annual Congress of the European Association of Nuclear Medicine, October 10-14, 2015, Hamburg, Germany
}

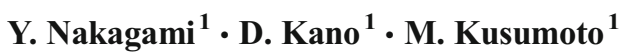

Published online: 9 March 2016

(C) Springer-Verlag Berlin Heidelberg 2016

Erratum to: Eur J Nucl Med Mol Imaging

DOI 10.1007/s00259-015-3198-Z

Bone scintigraphy as a new imaging biomarker: the relationship between bone scan index and PSA in prostate cancer patients receiving radium-223 dichloride therapy (Presentation Number: P747).

At the time of the meeting, the authors decided not to present their article at EANM 2015.

The online version of the original article can be found at http://dx.doi.org/ 10.1007/s00259-015-3198-z.

Y. Nakagami

ynakagam@east.ncc.go.jp

1 National Cancer Center, Chiba, Japan 